\title{
La comunicación pública de la oposición política en Cuba: indagaciones para un estado de la cuestión
}

\section{Public communication of the political opposition in Cuba: inquiries for the state of the issue}

\section{Cosette Celecia ${ }^{1}$}

Recibido el 29 de setiembre de 2016 - Aceptado el 12 de diciembre de 2016

\begin{abstract}
RESUMEN: Interesa aquí establecer un estado del arte sobre la comunicación pública de la oposición política en Cuba, pues en las revisiones sobre el tema no se encontraron estudios que relacionaran ambas nociones. Mientras, son escasos los estudios que abordan a la disidencia cubana en general. Para avanzar en una investigación que analice el modo en que se configura lo público en torno a la oposición en Cuba, una actividad ilegal y criminalizada, se impone un análisis que identifique los vacíos en la producción de conocimientos en esta área y rescate los elementos que permitan pensar contextualizada y críticamente el fenómeno.
\end{abstract}

Palabras clave: comunicación pública, oposición política, Cuba, estado de la cuestión

ABSTRACT: Interest here is to establish a state of the issue on public communication of the political opposition in Cuba, because in the reviews on the subject no studies relating both terms were found. Meanwhile, there are few studies that examine Cuban dissidence in general. To advance in research about how is the configuration of the public thing is set around the political opposition in Cuba, an illegal and criminalized activity, is imposed an analysis that identifies gaps in knowledge production about this subjects and rescue the elements which allow us to think, contextualized and critically, the phenomenon.

Keywords: public communication, political opposition, Cuba, state of the issue

1 Cosette Celecia es Maestra en Estudios de la Cultura y la Comunicación por la Universidad Veracruzana de México y Licenciada en Periodismo por la Universidad de La Habana, Cuba. Doctoranda del programa en Estudios Socioculturales del Centro de Ciencias Sociales y Humanidades de la Universidad Autónoma de Aguascalientes. cosettecelecia@gmail.com, http://orcid.org/0000-0002-2469-9317 


\section{Introducción}

En la isla la oposición política es ilegal. Un conjunto de disposiciones legales sustenta que los grupos y actividades de los disidentes políticos sean reprimidos por la oficialidad y que sus acciones sean criminalizadas. Mientras, el control estatal sobre la información y el monopolio del Estado sobre la radio, la televisión, la prensa escrita y no pocos espacios informativos en internet, determinan que desde los medios oficiales cubanos se construya una imagen del país carente de conflictos y disenso, en la que se resalta el apoyo popular al gobierno y sus disposiciones. Las voces disidentes en Cuba no sólo no tienen acceso a los medios de comunicación oficiales, sino que cuando son representados en ellos es desde la estigmatización y desde una impersonalidad que los deshumaniza y generaliza a su alrededor nociones negativas. Esa constante deslegitimación que se da desde lo factual, lo discursivo y lo simbólico provoca la exclusión social de los disidentes e influye en su desconexión con otros sectores de la sociedad civil. Pero pese a la ilegalidad de ciertas prácticas contestatarias, los disidentes políticos han podido cada vez con más frecuencia salir al extranjero y participar en foros, conferencias, debates y conversaciones con altos funcionarios de diferentes países.

Desde la salida de Fidel Castro del poder en 2006 y la asunción del poder por parte de su hermano Raúl, hasta el restablecimiento de relaciones diplomáticas con Estados Unidos en diciembre de 2014, numerosos cambios operados en la isla están relacionados con el auge público de las acciones de grupos disidentes y sus líderes. Dos medidas gubernamentales que han flexibilizado el acceso a la comunicación y así facilitado el acceso de la ciudadanía a la comunicación pública, han sido la legalización de la tenencia de líneas de telefonía celular en 2008, antes vedada a ciudadanos nacionales; y el aumento paulatino -aunque aún precario y excesivamente costoso- del acceso a internet a través de salas de navegación y zonas wifi en diferentes puntos del país.

Aunque en Cuba los niveles de acceso a Internet están aún entre los más bajos a nivel mundial y existen problemáticas como los límites impuestos a los contenidos, así como violaciones a los derechos de los usuarios (ITU, 2014; Freedom House, 2015, 2016), la red ha impulsado la conexión de miembros de la oposición, blogueros, activistas y periodistas independientes con medios de comunicación y agentes políticos en el exterior. También Internet ha facilitado que se generen desde Cuba espacios alternativos para la información y la deliberación de asuntos públicos en el contexto digital, todo lo cual desdibuja las fronteras físicas de lo público en relación con la oposición política que existe en Cuba.

También con el gobierno de Raúl Castro entró en vigor en 2013 una nueva Ley de Reforma Migratoria que permite a los cubanos viajar al extranjero sin necesidad de solicitar al gobierno el 
Permiso de Salida y sin la Carta de Invitación que debían emitir ciudadanos o instituciones del país de destino. Esta ley, que extiende la estancia de los cubanos en el extranjero hasta por dos años de manera legal, ha facilitado la salida al exterior de numerosos activistas y su participación en diferentes eventos fuera de la isla. No obstante, el estado continúa otorgándose el derecho de restringir la salida del país a voces críticas, como ocurrió con la artista plástica y activista Tania Bruguera, quien estuvo ocho meses sin poder salir de Cuba durante 2015, luego de que las autoridades nacionales le retiraran su pasaporte y la acusaran de "resistencia y desorden", debido a un proyecto de performance que consistía en colocar un micrófono en la Plaza de la Revolución de La Habana para que los ciudadanos expresaran sus opiniones sobre el futuro de Cuba.

De cualquier forma son numerosas las citas en el extranjero a las que acuden líderes y activistas opositores. La líder de las Damas de Blanco, Berta Soler, se reunió con el vicepresidente de Estados Unidos, Joe Biden, quien la recibió en la Casa Blanca en 2013; el presidente de Chile, Sebastián Piñera y diplomáticos de Costa Rica se entrevistaron con representantes de organizaciones opositoras durante la II Cumbre de La Comunidad de Estados
Latinoamericanos y Caribeños (CELAC), celebrada en La Habana en julio de 2014. Rosa María Payá mantiene una activa agenda de reuniones con políticos, académicos y activistas de diferentes países, fundamentalmente de Estados Unidos, la Unión Europea y América Latina, en busca de apoyo para su campaña Cuba Decide $^{2}$. Y durante noviembre de 2016 Guillermo Fariñas, líder del Frente Antitotalitario Unido (FANTU) se reunió en Estados Unidos con congresistas cubanoamericanos y con la embajadora de Estados Unidos ante las Naciones Unidas, Samantha Power.

En abril de 2015 Cuba asistía, por primera vez en cinco décadas, a la VII Cumbre de las Américas, celebrada en Panamá. La isla no había participado en estos encuentros pues fue excluida de la Organización de Estados Americanos (OEA) en 1962, debido a su alineación con el bloque soviético, de modo que su presencia en la cita acaparó la atención mediática. Durante esas jornadas la prensa brindó especial atención a la delegación cubana asistente al Foro de la Sociedad Civil, previo a la Cumbre y a los enfrentamientos que tuvieron lugar entre los integrantes de la llamada sociedad civil "socialista" -que contempla a las organizaciones civiles y de masas oficiales- y los representantes de la denominada sociedad civil "inde-

2 La campaña Cuba Decide propone la realización de un plebiscito que apoye modificaciones a la Constitución cubana. En el plebiscito los ciudadanos podrán aceptar o rechazar la pregunta: “¿Está usted de acuerdo con que se convoque a elecciones libres, justas y plurales, ejerciendo la libertad de expresión y de prensa; y organizándose libremente en partidos políticos y organizaciones sociales con total pluralidad? ¿Sí o No?” (Cuba Decide, 2016). 
pendiente" -conformada por las organizaciones opositoras y de defensa de derechos humanos no reconocidas por el gobierno-.

El presidente de los Estados Unidos, Barack Obama, durante su visita a Cuba se reunió, en la recién inaugurada embajada de Estados Unidos en La Habana, con líderes de los grupos opositores más visibles y activos del país. El 22 de marzo de 2016 tuvo lugar el encuentro al que asistieron Berta Soler, Fariñas, José Daniel Ferrer, de la Unión Patriótica de Cuba; Antonio Rodiles, de Estado de Sats; Elizardo Sánchez, portavoz de la Comisión Cubana de Derechos Humanos y Reconciliación Nacional; Yoani Sánchez, bloguera y directora del periódico independiente 14yMedio, Manuel Cuesta Morúa, líder del Partido Arco Progresista; la abogada y responsable de Cubalex, Laritza Diversent; el director de la revista Convivencia, Dagoberto Valdés; la bloguera Miriam Celaya; y la opositora Miriam Leyva (Diario de Cuba, 2016).

No necesariamente las voces disidentes con mayor presencia en lo público internacional son las de aquellos opositores con mayor o mejor trabajo dentro de la isla, pero ciertamente unos más que otros han logrado capitalizar su imagen con ayuda de agentes externos. Algunas de las figuras más conocidas de la oposición en Cuba han recibido importantes galardones internacionales que no sólo legitiman y reconocen su activismo, sino que aumentan su visibilidad en el contexto de lo público. Entre los laureados se encuentran la bloguera Yoani Sánchez, quien ostenta el Premio Ortega y Gasset de periodismo (2008) entre otros varios reconocimientos; Fariñas, a quien le fue otorgado en 2010, el Premio Sájarov a la Libertad de Conciencia que entrega el Parlamento Europeo, un reconocimiento que ostentan también las Damas de Blanco (2005) y el fallecido líder del Movimiento Cristiano de Liberación (MCL), Oswaldo Payá (2002).

De algunos como Fariñas y las Damas de Blanco resalta su persistencia. El primero suma ya 25 huelgas de hambre como protesta contra la represión gubernamental hacia los opositores, lo que lo ha colocado repetidamente en la agenda mediática internacional, sin que sus múltiples ayunos hayan conseguido otro tipo de resultados dentro de la isla. Mientras, las marchas semanales de las Damas de Blanco han sido seguidas por los medios extranjeros acreditados en la isla y también por medios independientes cubanos, que multiplican su presencia en lo público trasnacional y refuerzan el impacto visual de su performance. Su insistente presencia en calles cubanas y el simbolismo que se ha ido generando alrededor de su imagen, han hecho que resalten dentro del espectro opositor cubano.

La relevancia de Payá está dada por idear y dirigir el Proyecto Varela, un proyecto de ley que abogaba por reformas políticas a favor de mayores libertades individuales. Este proyecto se basó en el artículo 88 de la Constitución 
cubana de 1976, que permite a los ciudadanos proponer leyes si 10 mil electores registrados presentan sus firmas a favor de la propuesta. El MCL consiguió las firmas necesarias, pero no acreditaron la condición de electores de los firmantes, lo cual invalidó la propuesta que, no obstante, significó un hito por el apoyo recibido por numerosos ciudadanos, así como su repercusión internacional. Actualmente el Proyecto Varela sigue siendo impulsado a través del MCL y de la campaña Cuba Decide que lidera la hija de Payá.

Mientras, Sánchez se convirtió en una bloguera con miles de seguidores de todo el mundo, pese a las limitaciones tecnológicas y de acceso a internet. En su blog "Generación Y", iniciado en 2007, compartía su mirada personal y crítica sobre la cotidianeidad de la isla y las actualizaciones y traducciones a múltiples idiomas de sus publicaciones se apoyaban en la colaboración de voluntarios en el extranjero. Su activismo impulsaba así un tipo de oposición no tradicional que se valía no sólo de las nuevas tecnologías, sino además de redes de colaboración trasnacional.

Aunque sobre todos estos acontecimientos puede encontrarse basta información en diversos medios de comunicación, no se encontraron estudios académicos que los aborden desde las ciencias sociales. En este contexto, asumimos como objeto de estudio la configuración de la comunicación pública relativa a la oposición política de Cuba, lo cual implica un acercamiento no sólo a esos agentes, sino también a otros que convergen e interactúan con ellos. De modo que nuestro interés se centra en estudiar cómo los opositores, desde Cuba, establecen sus redes de colaboración, intercambio y flujos de información y quiénes potencian o frenan sus estrategias de intervención en los diferentes entornos de lo público, en un contexto en el que la inmutabilidad del sistema cubano en la arena política continúa invalidando su posibilidad de constituirse en una oposición legal, al tiempo que persiste y se incrementa su presencia en lo público trasnacional. Establecer un estado del arte que dé cuenta de lo estudiado hasta el momento sobre este tema permitirá detectar las brechas y los sesgos, orientar el análisis y recuperar nociones, conceptos y categorías.

\section{Primeras pistas}

Tras una revisión que permitiera evaluar el estado del arte acerca de nuestro objeto de estudio encontramos que no se han realizado investigaciones que conecten la comunicación pública - ni ninguna de sus fases: producción, difusión, retroalimentación - con la oposición política en Cuba durante el período revolucionario. Mientras, son considerablemente pocos los trabajos que abordan, aún tangencialmente, el tema de la oposición, teniendo en cuenta que ésta data desde el mismo triunfo de la Revolución, en 1959. Esta carencia en torno al abordaje del núcleo temático 
que es nuestro interés llevó a seleccionar, por una parte, los aportes de investigaciones que ofrecieran una panorámica general acerca de cuáles han sido las preocupaciones y también los vacíos en torno al estudio de la disidencia política emanada de iniciativas de la sociedad civil de la isla. En un eje independiente recuperamos los aportes de investigaciones que hubiesen trabajado la noción de comunicación pública que asumimos aquí y que se define como "el conjunto de fenómenos de producción, tratamiento, difusión y retroalimentación de la información que refleja, crea y orienta los debates y los temas públicos" y que contempla no sólo "el quehacer de los medios, sino también de las instituciones, las empresas, los movimientos y los grupos que intervienen en la plaza pública" (Como se citó en Demers y Lavinge, 2007, p.67).

Finalmente, encontramos que el Ejército Zapatista de liberación Nacional (EZLN) de México, debido a sus características, el contexto en el que emergió y sus estrategias de proyección pública, presentaba similitudes con los grupos opositores en Cuba y su relación con lo público. Trabajos académicos que han estudiado la comunicación pública del EZLN, han sido recuperados aquí debido a que sus abordajes complementan los dos ejes temáticos anteriores y sus hallazgos han catalizado también premisas de trabajo.

Los materiales elegidos se agruparon en tres grupos que abordan los siguientes tópicos generales:
- Sociedad civil en Cuba: voces disidentes

- Abordaje de la noción de comunicación pública

- Experiencias mediáticas de grupos minoritarios con estrategias comunicativas contestatarias y alternativas.

\section{Sociedad civil en Cuba: voces disi- dentes}

Las campañas de descrédito hacia la oposición política en Cuba por parte del discurso oficial durante más de cinco décadas, unido a una fusión en el ámbito simbólico nacional que homologa patria, soberanía e independencia con el proyecto socialista de la revolución (Bobes, 2007), tributan a la falta de legitimidad de estos grupos, cuyo prestigio y credibilidad se ve afectado también por no pocos errores de estrategia de sus integrantes. Mientras, sus vínculos con el gobierno de Estados Unidos facilitan que se les asocie con intereses entreguistas y antinacionalistas. Este orden de cosas tiene su reflejo en la producción académica generada desde la isla acerca de este tema.

La producción de conocimiento sobre la sociedad civil en Cuba, desde la academia cubana, ha eludido en general el abordaje de la oposición política, una ausencia que puede deberse a la situación antes descrita, así como a la dispersión y poca visibilidad e incidencia social de estos grupos, todo lo cual dificulta el trabajo de campo. Hay estudios que analizan las transformaciones en el entra- 
mado social a raíz de la crisis de los años 90, tras el colapso de la Unión Soviética y la desintegración del campo socialista -sostén económico de Cuba- y más recientemente, en el contexto de la apertura al mercado propiciada por los cambios en el modelo económico impulsados por el gobierno de Raúl Castro. En estos análisis se evidencia cómo, primero la crisis y luego la reforma, han provocado cambios sociales y estructurales que rompen con la anterior homogeneidad social que caracterizaba al país, favoreciendo la emergencia de nuevos actores y socialidades. En este escenario han sido centro de atención fundamentalmente los trabajadores del ascendente sector privado.

El tema de la oposición, cuyo auge está inscrito en este mismo contexto, ha sido el gran ausente en esos estudios, con excepción del trabajo de José A. Toledo García (2006) -sobre el que volveremos más adelante-, quien defiende la necesidad del análisis acerca de la oposición política en el proceso revolucionario. En otros casos, los estudios desde Cuba se enmarcan en el estudio de la sociedad civil "socialista" y aunque pueden ser muy críticos con el sistema participativo de la isla y abogan por una mayor democratización de lo público, circunscriben esos derechos a los grupos que respaldan el sistema político. Este es el caso de los trabajos de Juan Valdés Paz (1997), Olga Fernández (2011) y Marta Núñez (2014).

Valdés (1997) resalta el empoderamiento ciudadano propiciado por la revolu- ción cubana, cuyas transformaciones sociales produjeron una acelerada disolución de la sociedad civil tradicional.

Las nuevas relaciones sociales, el predominio de las relaciones de cooperación y la simplificación de la estructura social a clases y capas aliadas en el proyecto socialista propiciaron la unidad y la homogeneización de una sociedad civil, caracterizada en los años sesenta y setenta por una escasa diversidad, una alta exposición al sistema político y por el predominio de las organizaciones de masas como forma universal de asociación sectorial de la población (Valdéz, 1997, p.289).

Desde fines de la década del setenta del pasado siglo y de manera acelerada en la década de los 80 y 90 , la nueva sociedad civil fue emergiendo como expresión de la pluralidad de relaciones, actores e intereses, surgidos en el marco de las nuevas condiciones sociales y económicas aunque, señala Valdés (1997), es insuficiente su desarrollo debido en parte a la resistencia a su expansión "que plantea un sistema político desmesurado y presionado por las exigencias de la seguridad interna y externa" (pp.289-290). En opinión de este autor la sociedad civil "socialista", en la que se enfoca su trabajo, se caracteriza por la unidad nacional y una alta socialización y autonomía del Estado.

Fernández (2011), por su parte, aborda la institucionalidad y la participación popular como elemento fundamental en el 
contexto de las transformaciones del gobierno de Raúl Castro. Para esta autora la actualización del modelo económico y la preservación de la justicia social constituyen el núcleo de ese proceso, que a la vez debe tributar a la reanimación y profundización de la participación popular. En su trabajo, Fernández (2011) enfatiza el marco institucional que regula y debe potenciar la participación, supervisado por el Partido Comunista de Cuba, reclama ampliar el involucramiento popular como requisito para el desarrollo hacia el socialismo y sugiere sumar a los nuevos actores que identifica en el emergente sector del trabajo privado. Su análisis, con bases teóricas en el marxismo, refiere la necesidad de la socialización del poder político, así como de la deliberación pública permanente que garantice el empoderamiento popular, pero una vez más delimita estos derechos a la sociedad civil "socialista", quedando excluidos, también aquí, los miembros de grupos opositores o disidentes.

Núñez (2014) revisa los informes al presidente de las Comisiones de Asistencia para una Cuba libre (CAFC 2004 y 2006) y los resultados de dos seminarios de la Brookings Institution, acerca de la política de Estados Unidos hacia Cuba para apoyar una transición democrática en la isla. Este trabajo permite sistematizar los cambios en la política exterior de la administración de Obama hacia Cuba, que marcan una diferencia sustancial a la mantenida por los gobiernos estadounidenses de los últimos 50 años. Entre las nuevas medidas estadounidenses que favo- recen a los grupos disidentes de la isla destacan un programa de asistencia a la sociedad civil, la concesión de fondos para actividades centradas en los derechos humanos, las microempresas y la formación profesional; así como facilitar el acceso tecnológico y a la comunicación. En los informes de la Brookings Institution se documenta la realización de seminarios para mejorar la comprensión sobre las realidades políticas de Cuba y los Estados Unidos e identificar posibles catalizadores y limitaciones a los cambios políticos en la isla. Aunque estos documentos evidencian el apoyo a la sociedad civil opositora generado desde Estados Unidos, también en ellos se señala que pocos cubanos reconocen a los movimientos disidentes como alternativa simbólica o práctica y admiten que el apoyo internacional puede ser el único hacia ese movimiento (Núñez, 2014).

Estos trabajos permiten dar cuenta de cómo el discurso oficial y la pertenencia al sistema político atraviesan el discurso académico nacional acerca de la disidencia y reproducen los marcos simbólicos de exclusión y pertenencia a la sociedad civil y a la ciudadanía. También se recupera de estos abordajes el análisis de los nexos de la oposición política cubana con grupos y organizaciones ligadas al gobierno estadounidense. El apoyo económico y estratégico que los agentes foráneos ofrecen a los opositores de la isla permite establecer como premisa de trabajo que las formas de financiamiento, las estrategias comunicativas y la formación de capital humano 
entre los grupos opositores, están mediadas por prácticas de colaboración en las que intervienen agentes extranjeros, con intereses políticos particulares que atraviesan la agenda y las proyecciones públicas de los opositores cubanos. Este tema resulta en extremo polémico, pues los criticados vínculos de la disidencia con el gobierno de Estados Unidos se producen en un contexto en el que el carácter ilegal de la oposición en Cuba obstaculiza otros modos de financiamiento.

Toledo (2006, p.3) analiza "el contenido y las formas de lucha y la ideología de los sujetos que antagonizan en el proceso revolucionario emancipador tomando como base para este análisis la metodología dialéctico-materialista, en particular de aquellos conceptos y categorías relacionadas con el conflicto revolución-contrarrevolución y la fundamentación ideológica del antagonismo". Este autor explica que el abordaje de la oposición política cubana resulta un problema de gran actualidad relegado en general por la academia cubana y atendido, fundamentalmente, por la literatura de ficción o histórica. Nuestra investigación, por tanto, contribuiría a llenar esas brechas de conocimiento, al aportar una reflexión acerca del desempeño de los grupos opositores en relación con lo público, dentro de régimen socialista de estado que en los últimos años ha impulsado una apertura al mercado.

En la investigación de Toledo (2006) no se explicita un posicionamiento frente al objeto de estudio, pero en su informe se percibe el rechazo del que parte su mirada a la disidencia, a la que llama "contrarrevolución" como par antitético y negativo del positivo "revolución". Esto se advierte, por ejemplo, cuando al explicar la pertinencia de su estudio refiere que si bien en las ciencias sociales cubanas se suele argumentar con mucha fuerza la importancia de la revolución, "se olvida la otra cara de la moneda, el otro polo que impide, frena y entorpece la marcha de la gran "locomotora de la historia' al decir de Marx" (Toledo, 2006, pp.3-4).

También encontramos que algunos autores afiliados a instituciones cubanas han estudiado prácticas contestatarias de grupos de la sociedad civil, cuyas acciones representan una disidencia, pero no propiamente una oposición. Tales grupos, que reúnen a artistas e intelectuales, asumen discursos críticos hacia el poder, pero desde la pertenencia al proyecto revolucionario y no desde la desafección. Al hablar de oposición o disidencia política, entendemos por tanto, a aquellos actores que pertenecen a grupos con proyectos de trasformación. En otro campo político situamos entonces a actores que, aun manteniendo posiciones críticas, asumen a los dirigentes cubanos como interlocutores legítimos y no aspiran, al menos explícitamente, a ser opción de poder alternativo. Entre estos últimos se incluyen algunos intelectuales, activistas, académi$\cos$ y blogueros oficiosos (Dilla y Oxhorn,1999; Dilla, 2014). Estudios que abordan a este último grupo resultan los de Ivette Leyva y Abel Somohano (2008) y Nora Gámez (2013). 
Leyva y Somohano (2008) exponen las características de la esfera pública cubana a partir de la irrupción de internet y del uso del correo electrónico para abordar temas políticos en una coyuntura específica ${ }^{3}$. Los autores sostienen que a partir del intercambio electrónico, entre intelectuales fundamentalmente, que tuvo lugar en 2007, se podría hablar de la creación de "esferas públicas periféricas" en la isla y resaltan cómo con las nuevas tecnologías la interacción ciudadana dentro del país se complejiza ante la aparición de alternativas para construir intercambios en los que se expresen opiniones invisibilizadas cotidianamente. Los autores, que se declaran en el texto defensores del proyecto de nación socialista, plantean que la supervivencia del proyecto social de la revolución requiere, entre otras cosas, de "la contribución del criterio -y la acción- no sólo de los intelectuales, sino de aquellos que desde una posición orgánica al sistema aprovechen todas las herramientas a su alcance, para extender sus posicionamientos críticos protectores de nuestra Revolución" (Leyva y Somohano, 2008, s/p). Su llamado final a una participación más activa en el debate de temas públicos queda así circunscrito a aquellos que apoyan el sistema.

Gámez (2013), a partir de un estudio del hip-hop cubano examina cómo la música puede convertirse en una práctica de oposición política en una sociedad socialista como la cubana. Su estudio se basa en el análisis de letras de canciones e intervenciones públicas del grupo Los Aldeanos, e ilustra cómo estos raperos re articulan el imaginario de la revolución cubana para proponer una política de confrontación radical hacia el estado, con lo cual construyen lo que ella denomina "una identidad revolucionaria subversiva". Para esta investigadora la música de Los Aldeanos puede interpretarse como una forma de práctica política en un contexto donde la asociación política $u$ otras formas de movilización cívica están restringidas y afirma que el caso de estos raperos permite ilustrar las complejas relaciones entre música, estado y política en el socialismo. Vale retomar de aquí las referencias al escenario político cubano y a los mecanismos de control y represión hacia los discursos disidentes, así como las estrategias que emplean algunos actores para socializar un discurso contestatario en ese contexto.

Entre la diáspora académica la oposición ha recibido mayor atención como grupo perteneciente a la cada vez más diversificada sociedad civil cubana. Estas miradas de cubanos desde el extranjero se han enfocado en aprehender cambios generales que permiten

3 Los autores abordan las características de la esfera pública cubana a partir del análisis de la polémica entre intelectuales cubanos que tuvo lugar en enero de 2007, que se desarrolló mediante correos electrónicos y versó alrededor de las políticas culturales revolucionarias de los años 70 y sus secuelas, a raíz de la presencia de censores de la época en determinados espacios televisivos en calidad de invitados y homenajeados. 
constatar las transformaciones de los últimos diez años en la isla y sus impactos generales en lo social, lo económico, lo político, lo cultural, a veces también desde una perspectiva comparada que pone en diálogo la realidad cubana con la de otras naciones. Se incluyen aquí los trabajos de Haroldo Dilla y Philip Oxhorn (1999), Dilla (2014), Cecilia Bobes (2007), Eusebio Mujal Leon y Eric Langenbacher (2009); y Armando Chaguaceda y Marie Laure Geoffray (2014). Sus análisis proporcionan elementos para evaluar a la oposición desde miradas globales que permiten entender la disidencia política en el contexto cubano como una forma de negación de la ciudadanía y constatar tanto sus limitaciones en la arena política, como los recursos que les permiten desafiar el control estatal sobre lo público nacional.

Dilla y Oxhorn (1999) y Dilla (2014) explican cómo con el triunfo de la revolución la clase política emergente fue generando una serie de organizaciones sociales y de masas y enfatizan que su característica general es la relación con el Estado como "correas de transmisión” en el clásico esquema centralizado verticalista. Estos autores se refieren además a la definición de "sociedad civil socialista" formulada por la oficialidad cubana a fines de los años 90, circunscrita a las organizaciones sociales y de masas tradicionales y las ONG's consideradas aceptables por el sistema. A diferencia del criterio de Valdéz (1997), para estos autores, los grupos de la sociedad civil oficial, constituyen un um- bral impreciso entre la sociedad civil y el Estado debido a la pobre autonomía que han mostrado en sus proyecciones públicas.

Para Dilla y Oxhorn (1999) la disidencia cubana está constituida por "grupos escuálidos de oposición política" que reclaman estatus legal y enfocan sus pronunciamientos fundamentalmente al tema de los derechos humanos y señalan que su inclusión en la sociedad civil es muy problemática debido a que se trata de numerosos grupos muy pequeños con escasa o nula influencia en la vida nacional, o incluso local y porque están compuestos mayoritariamente por personas que aspiran a emigrar a Estados Unidos, lo que contribuye a su inestabilidad organizativa y de membresía. Su trabajo también se interesa por la relación que existe entre la política de Estados Unidos hacia Cuba y las reacciones de hostilidad del estado y el Partido Comunista de Cuba hacia la sociedad civil opositora, debido a que la disidencia se asocia a los intereses norteamericanos, lo cual sirve como justificación al gobierno para ejercer sus mecanismos de control sobre estos grupos.

Por otra parte, el hecho de que el régimen político impida la comunicación de la oposición con la sociedad cubana les dificulta insertarse en el escenario público nacional, de modo que su principal interlocutor resulta un segmento politizado y polarizado de la emigración (Dilla, 2014). Es importante tener en cuenta entonces que si bien el gobierno cubano resulta un agente cuyas 
estrategias frenen la comunicación pública de la oposición, otros, como el gobierno estadounidense, mantienen estrategias para potenciarla, lo cual sucede, no obstante, dentro de ciertos límites.

Las conexiones con agentes foráneos propician el empoderamiento de los grupos opositores en Cuba y promueven su visibilidad fuera de la isla a través de estrategias de comunicación convencionales como la cobertura mediática y la participación en diferentes eventos. Mientras, la comunicación sobre la oposición dentro de la isla emplea variantes alternativas como la información que pasa de mano en mano en memorias flash, o la impresión casera de textos y revistas que también son distribuidos personalmente y de manera gratuita. Así los opositores evaden los controles estatales sobre lo público en Cuba para hacerse presentes hacia adentro y hacia afuera del país. Estas estrategias combinan recursos tradicionales con otros contingentes y exiguos, pero originalmente adaptados para sobrevivir en un contexto adverso. En ambos casos, la comunicación fluye mayoritariamente entre un público de cierta forma cautivo, que se circunscribe a los propios opositores y sus simpatizantes, con frecuencia protagonistas, productores y consumidores de la información sobre el tema. Se genera así una comunicación pública que si bien se estructura como un proceso continuo y variable, se presenta también con un carácter circular, en el que se pueden establecer diferentes órbitas, pero todas ligadas a una comunidad que comparte la desafección al régimen político cubano y que espera su transformación.

Bobes (2007), por su parte, ayuda a entender el extendido rechazo que experimenta la oposición dentro de Cuba a partir del análisis de procesos históricos de larga duración, a través de los cuales "el arraigo de una cultura política marcada por el nacionalismo beligerante 5 la intolerancia y la moralización de la política, ha generado una definición de la nación desde lo político y ético que siempre es excluyente respecto a otro" (p. 14). Su revisión, que inicia en el siglo XIX y se extiende hasta la actualidad, esclarece muchas de las complejidades del proceso revolucionario que se expresan en la simbiosis de una vocación democrática y participativa por un lado y una estatista y de ritualización de la participación por otra. Su estudio problematiza cómo con la radicalización e institucionalización del proceso revolucionario las alternativas individuales, la innovación y la autonomía se cancelaron o desplazaron a zonas restringidas de la vida privada. Bajo estas condiciones se instauró el principio de la unanimidad como la conducta más deseable, se canceló la pluralidad y se justificó la exclusión de las minorías, 
particularmente de los disidentes, definidos como enemigos y marginados de la pertenencia legítima a la comunidad política y a la sociedad civil (Bobes, 2007).

Mujal-Leon y Langenbacher (2009) repasan los procesos que pueden estar contribuyendo a un cambio de régimen o democratización en la isla, estableciendo paralelos con otros procesos de transición de regímenes autoritarios y tomando en consideración el papel de la sociedad civil cubana y de la diáspora. Para ellos el régimen cubano enfrenta tres retos coincidentes que son: un proceso de sucesión en curso, una transición de régimen, y la economía en una situación desesperada que debe estabilizarse; todo lo cual sucede en un contexto caracterizado por una recesión democrática a nivel mundial y el resurgimiento en la región de regímenes híbridos, semi-autoritarios, un contexto en además en el que ya no se percibe la democracia como el producto inevitable de un régimen de transición (Mujal-León y Langenbacher, 2009, pp. 37-38). Estos autores toman como referencia la experiencia de la transición en Europa del Este y resaltan del caso de Polonia el importante papel de la sociedad civil, así como el de Alemania del Este, “cuya rápida y dramática desestabilización muestra lo que una crisis de emigración puede producir y la rapidez con que la oposición puede florecer incluso con una pequeña apertura" (Mujal-León y Langenbacher, 2009, p. 38 ), casos que invitan a no perder de vista las múltiples interconexiones que atraviesa también nuestro objeto de estudio.

Según las predicciones de Mujal-León y Langenbacher (2009), los escenarios más probables en Cuba son cuatro: volver a las estrategias de movilización y a las políticas más ortodoxas del pasado; lograr una consolidación pos totalitaria o una evolución hacia una forma no totalitaria del autoritarismo; que la actual élite dirigente sea capaz de permanecer unida y de superar los numerosos problemas económicos de la isla; y por último la opción democrática, ya sea por el colapso del régimen, o por el "desarrollo de un sector considerablemente 'reformista' dentro del régimen que esté dispuesto a negociar con la oposición política y los representantes de los movimientos sociales y de masas y la sociedad civil independiente"(p. 40).

Los autores consideran poco probable el último escenario, pues en su opinión, en ausencia de Fidel y Raúl Castro los conflictos internos dentro de la coalición de gobierno son más probables. En tanto consideran que una sociedad civil más organizada y resuelta a transitar de las demandas económicas y sociales hacia las reivindicaciones más explícitamente políticas, podría proporcionar una base social para la movilización y la protesta. Para estos autores, además, la diáspora cubana podría convertirse en un jugador importante en cualquier escenario de transición, pues representa aproximadamente el 15 por ciento de la nación cubana y cuenta con amplios recursos, entre ellos, la capacidad de influir 
en la política de Estados Unidos (MujalLeón y Langenbacher, 2009).

También preocupados por los síntomas de un no declarado cambio político en la isla, Geoffray y Chaguaceda (2014) abordan el caso cubano en el tránsito de un modelo prototípicamente soviético, con censura y control cuasi total de la información por parte del estado, a otro donde la aparición de nuevos actores y medios modifican la relación entre información, comunicación y política, acotando la hegemonía del discurso oficial. Al describir las políticas informativas y las relaciones medios-poder en Cuba, estos autores distinguen tres periodos: el primero, de los años 60 hasta la caída del muro de Berlín, se corresponde con el modelo clásico de relación prensa-poder característico de los regímenes de corte soviético; en el segundo, de los años 90 hasta la emergencia de usos informativos del internet, aparece el periodismo independiente en la isla y se incrementan la opinión y la crítica en publicaciones oficiales; mientras el tercero, se inicia a mitad de los años 2000, cuando emergen nuevos actores de la información y se pluraliza la esfera y el debate público, fundamentalmente en la red (Geoffray y Chaguaceda, 2014). El tercer período, que se extiende hasta la actualidad, describe el contexto cubano de relaciones medios-poder en el que se ubica nuestro estudio.

Los grupos de la sociedad civil que se desarrollan al margen del estado cubano también se han constituido en objeto de estudio para académicas foráneas: María Aristigueta (2008) y Marie Laure Geoffray (2012) han aportado desde sus miradas particulares a este tema, completando un cuadro bastante amplio y heterogéneo de estudios que atraviesan la temática de la oposición política en Cuba. Aristigueta (2008) analiza un grupo de proyectos desarrollados por la sociedad civil no gubernamental en Cuba: Cubanet, un medio de prensa digital sin fines de lucro dedicado a promover la prensa alternativa en Cuba y a apoyar a la sociedad civil de la isla; la Red Nacional de Bibliotecas Comunitarias Independientes, las Misiones de Médicos Independientes; y NaturPaz. Como el resto de los autores revisados hasta aquí, Aristigueta (2008) señala que la mayoría de las asociaciones no gubernamentales en Cuba operan fuera del ámbito de lo que el gobierno considera legal y entre su trabajo resalta como elementos positivos de esas organizaciones independientes su transparencia y responsabilidad, su contribución a la expansión de los servicios y la creación de nuevas instituciones y el fortalecimiento de la comunidad.

Esta autora se refiere también a los métodos represivos que emplea el estado cubano contra los grupos disidentes y analiza su fragmentación en tal contexto, a la vez que reconoce el trabajo que han desarrollado, pese a los contratiempos, tanto los proyectos que toma como unidades de análisis en su trabajo, como otros grupos y proyectos opositores entre los que cita a Concilio Cubano, el Grupo de Trabajo de la 
Disidencia y el Proyecto Varela. Muchos de estos grupos y proyectos se disolvieron sin dar los resultados esperados, o siguen trabajando a nivel comunitario sin gran visibilidad a nivel nacional, pero cada uno ha contribuido al desarrollo de la denominada sociedad civil independiente cubana y forma parte de su continuidad (Aristigueta, 2008).

Geoffray (2012), por su parte, busca entender cómo se da el disenso en el contexto autoritario cubano a partir del análisis de espacios de crítica que se generan con cierta autonomía del estado y a nivel local, lo cual favorece que estas iniciativas no sean desactivadas ni completamente reprimidas, aunque tampoco sean totalmente toleradas. Los actores que estudia se encuentran en los límites del campo intelectual y artístico y su postura política hacia el régimen también resulta ambigua ya que no se asumen como opositores, pero tampoco como simpatizantes del régimen. Entre los colectivos que estudia se encuentran el proyecto Ovni Zona Franca, La Joven Cuba y raperos del movimiento de hip hop cubano. Estos grupos han podido negociar con las autoridades su permanencia y esa tolerancia a los espacios de expresión crítica y de acción colectiva a nivel micro es generadora de espacios de participación ciudadana.

En la producción de conocimiento acerca de la sociedad civil cubana y sus voces disidentes un elemento recurrente es el análisis acerca de las nuevas tecnologías en la modificación de lo público en la isla, lo cual ha favorecido los usos de internet con fines contestatarios y ha pluralizado y complejizado el entorno de lo público. Particularmente nos interesa enfatizar cómo las nuevas tecnologías desdibujan los límites entre lo local, lo nacional y lo global; vuelven la información inmediata, fragmentada, fugaz; transforman prácticas y estrategias; y detonan una comunicación multisituada y trasnacional, que desborda los espacios geográficos tradicionales y posibilita la emergencia de nuevos entornos comunicativos, no ya concretos o delimitados, sino estructurados a partir de una pertenencia cultural. Con todo esto lo público se vuelve extensible y aunque los procesos en este ámbito se configuren a diferentes escalas más o menos dilatadas, cada una coexiste y se interconecta con el resto, en una interacción continua y flexible.

Uno de los aportes de nuestro estudio es entonces asumir lo público como una noción glocal, estructurada a partir de diferentes niveles de configuración, permeables entre sí, que pueden extrapolarse a un ámbito simbólico. Y es que al referirnos a la configuración de la comunicación pública concerniente a la oposición política de Cuba, a partir de las interacciones de los agentes que median este proceso, no podemos definir una comunicación ligada a un territorio, ni físico, ni virtual. Los medios, recursos y estrategias que emplean los agentes que intervienen en ese proceso configuran un espacio público simbólico que es donde esa propia comunicación pública acontece. 
Podemos resumir además que los estudios que abordan de modo más específico a grupos y experiencias disidentes o contestatarias pueden agruparse en tres corrientes: los que se centran en las voces y el discurso de grupos críticos pero integrados al sistema; los que atienden experiencias de colectivos alternativos, cuyo compromiso político resulta variable y poco definido; y los que abordan a la oposición política. En este último grupo se inserta nuestro estudio, con la intención de aportar, desde la comunicación pública, a las miradas que se han hecho a ese conjunto diverso y complejo que resulta la sociedad civil cubana actual, en la que cada miembro resulta una pieza clave.

\section{Abordaje de la noción de comunica- ción pública}

En este eje encontramos que los autores articulan junto a comunicación pública otros conceptos como espacio público, consenso, poder, debate público, opinión pública, entre otros. Y si algo resalta en cada uno es la preocupación por los múltiples abordajes que puede tener la comunicación pública y, por tanto, la polisemia del término. La mayoría de los autores revisados se demarcan de las concepciones de Jürgen Habermas acerca del espacio público y de la deliberación pública entendida como debate racional, para reformular su propuesta considerando el contexto actual, mediado por nuevos espacios de lo público que configuran las nuevas tecnologías, la globalización, las asociaciones y orga- nizaciones no gubernamentales, los espacios públicos parciales y la disminución del estado de bienestar frente a estructuras más eficientes. Estas realidades contemporáneas han llevado a los investigadores a ampliar los horizontes teóricos y analíticos sin restringir la argumentación a su dimensión racional y a determinados temas o espacios de lo público.

Salvador De León (2011) aborda la configuración de la comunicación pública en una sociedad en transición, como la mexicana, a partir del análisis de la relación entre periodistas, propietarios de medios, políticos y otros actores que intervienen en el ámbito de lo público, a partir de un estudio situado en el estado de Aguascalientes. Sus hallazgos se vinculan con las transformaciones políticas y la apertura económica ocurridas en México desde la década de 1990 y parten del supuesto de que la configuración de la comunicación pública cambia porque las condiciones políticas y económicas se han transformado. De tal modo, el abordaje teórico metodológico de su objeto aporta útiles referentes al análisis del nuestro, inserto igualmente en un contexto de cambios. Su mirada a lo local mediado por lo global, es una perspectiva ineludible para nuestro trabajo; así como su apropiación de la noción de comunicación pública, a partir de autores como Beauchamp, Demers y Lavigne y la sistematización del término en su caso de estudio.

Desde otra línea de trabajo Guylaine Proulx (2007) se interesó por el papel 
de los medios de comunicación en la construcción de las representaciones sociales acerca de temas medioambientales, para lo cual desarrolló un estudio de recepción mediática, entendida como práctica social mediante la cual los individuos reconstruyen el discurso mediático en función de su posición al interior de una "comunidad interpretativa” específica. Dicha comunidad se define como instancia semiótica y social en cuyo interior se producen y se estabilizan ciertos modos de interpretación del discurso mediático. Es precisamente esta propuesta de comunidad interpretativa lo que llama nuestra atención, así como sus hipótesis sobre las experiencias sociales que podrían constituir los fundamentos de algunas comunidades interpretativas específicas, lo cual apoya nuestro interés en pensar en una dimensión simbólica ligada a la comunicación y a lo público que crea comunidad, que refuerza identidades, tal como presuponemos que sucede con la configuración de la comunicación pública relativa de la oposición política cubana.

La investigación de Marie-Christine Morin (2009) también ofrece algunas pistas para pensar en territorios simbólicos mediados por la comunicación pública. El tema surge por su preocupación ante la desaparición del barrio chino de Quebec a la par de su presencia virtual en Internet, de manera que se propone explorar el potencial que tendría el barrio chino virtual de esa ciudad canadiense para reemplazar a su referente físico. De su trabajo reto- mamos igualmente las reflexiones en torno a la constitución de comunidades virtuales potenciadas por las nuevas tecnologías, pero amalgamadas a partir de referentes culturales compartidos.

También en el entorno virtual, Julie Debaveye (2013) analiza el surgimiento y la institucionalización de una experiencia militante en Twitter: la Convergence de Luttes Anticapitalistes (CLAC), en Quebec, a partir de la observación de dinámicas sociales e intertextuales del grupo con otros medios militantes, alternativos y globales, durante la Cumbre del G-20 en Toronto, en 2010 y la huelga estudiantil conocida como Primavera Arce (Printemps Érable) de 2012 en Quebec. Llama la atención de su propuesta el uso de métodos mixtos para la exploración, análisis e interpretación de prácticas mediáticas de un grupo en redes sociales, así como el estudio de formación de públicos de nuevos medios en un contexto de crisis política. Debaveye (2013) estudia la especificidad de las comunicaciones militantes en lo que denomina micro-medios de comunicación -refiriéndose a Twitter-, y sus dinámicas de influencia y de poder en las esferas políticas locales. De tal modo su estudio también aporta ideas acerca de cómo estudiar comunicaciones sobre temas políticos, a través de espacios en internet teniendo en cuenta los modos de transmisión de información local a escala global.

El abordaje de la comunicación pública revisado presenta, también desde diferentes abordajes metodológicos, el con- 
texto digital como espacio de convergencia, de diálogo, de expresión identitaria y de movilización política que transforma lo público tradicional. Estos estudios demuestran que las nuevas realidades demandan nuevos enfoques analíticos que aporten miradas transversales a lo micro, lo meso y macro sociocultural. Consideramos importante rescatar para nuestro estudio el bagaje teórico que contienen estos trabajos acerca de la comunicación pública y recuperar nociones como "comunidad interpretativa” (Proulx, 2007) y "comunidad virtual" (Morin, 2009). Aunque la comunicación pública puede tratarse desde diferentes perspectivas, tal como se aprecia en los trabajos revisados, nuestra investigación se plantea a partir de una noción integral de la comunicación pública, más cercana a la propuesta de De León (2011), en la que se privilegie el análisis de las (inter) relaciones entre agentes que intervienen en la configuración de lo público. Además, asumimos lo público como una noción global y nos interesa comprender la configuración de lo público mediado por la pertenencia a una comunidad cultural y por la comunicación ligada a ámbitos simbólicos.

\section{Experiencias mediáticas de grupos minoritarios...}

Conectado con nuestros intereses por el tipo de objeto de estudio y sus análisis, encontramos varios artículos que abordan las estrategias comunicativas del EZLN. Guiomar Rovira (2005) exa- mina cómo el levantamiento armado de este grupo, el primero de enero de 1994 en Chiapas, en el sudeste de México, encontró resonancia fuera de las fronteras nacionales y generó una red de solidaridad transnacional con otros movimientos sociales. Estos movimientos, geográficamente dispersos, se sostenían a través de redes, por tanto, su estudio nos permite acercarnos al análisis de una forma de acción política articulada por estrategias de comunicación transnacionales, tal como sucede con la oposición política que opera dentro de Cuba.

En 1994 la World Wide Web cumplía un año de existencia y el uso de Internet se extendía exponencialmente entre determinados sectores de la población mundial, principalmente en universidades y entre periodistas. En este escenario la primera página electrónica sobre Chiapas, la crearon voluntariamente dos estudiantes de Estados Unidos, mientras se sumaban espontáneamente y de forma anónima "quienes traducían los comunicados y las notas a multitud de lenguas y los difundían mediante forwards y listas de emails" (Rovira, 2005, s/p).

En la red del zapatismo transnacional se pueden identificar distintos niveles en la generación y difusión de la información. En el centro, están las comunidades indígenas y los discursos del EZLN. A su alrededor, en un segundo nivel, están quienes elaboran la información en Chiapas para su difusión; las organizaciones no gubernamentales 
mexicanas y extranjeras instaladas en Chiapas; los activistas y los miembros de colectivos de solidaridad que acuden a las comunidades zapatistas y elaboran denuncias e informes (Rovira, 2005). Tomando en cuenta esta experiencia, parece útil definir, a partir de nuestra premisa acerca del carácter circular de la comunicación pública relativa a la oposición en Cuba, las órbitas más significativas que pueden identificarse en relación con nuestro objeto, así como ubicar a los agentes que intervienen en cada una. Este ejercicio demanda trabajo de campo y podría ser un recurso de sistematización al momento de presentar los resultados, pero de cualquier forma, la revisión del estado del arte permite enunciar de antemano al menos tres circuitos fundamentales en los que se configura la comunicación pública sobre la disidencia: uno local, uno nacional y uno trasnacional; con la particularidad de que si los protagonistas en la primera y tercera órbita son agentes que potencian el proceso, en el nivel intermedio, donde lo público está monopolizado por el estado cubano, las estrategias fundamentales están dirigidas a limitarlo.

Entre las acciones que el zapatismo transnacional ha empleado para defender la causa de los indígenas de Chiapas se pueden clasificar cuatro grandes rubros: manifestaciones y encuentros en diferentes ciudades del mundo para dar a conocer la situación de ese estado, influir en la opinión pública local y presionar en las delegaciones diplomáticas mexicanas; campa- ñas de presión hacia las élites locales para que a su vez presionen al gobierno de México; afluencia de extranjeros a las comunidades indígenas que sirvieron de multiplicadores de la causa y tejieron relaciones interpersonales; y la desobediencia civil electrónica en Internet (Rovira, 2005).

En el caso de la oposición cubana de la isla también se aprecian diferentes tipos de acciones comunicativas y de intervención en lo público local y transnacional, tanto por parte de los opositores como de los agentes externos que interactúan con ellos en ese entorno. Teniendo en cuenta los elementos que se enfatizan en cada una de las estrategias que desarrollan esos agentes podemos clasificarlas en:

1- Performáticas (Intervenciones en lo público físico y virtual cuyo énfasis está en el proceso, en la representación, en lo simbólico. Por ejemplo, las marchas de las Damas de Blanco).

2- Discursivas (Relativas a toda intervención discursiva, ya sea presencial, mediante los medios de comunicación masiva o las plataformas en internet).

3- Antisistémicas (Proyectos concreto cuya finalidad es modificar el régimen político de Cuba: proyectos de leyes, referéndum, programas políticos).

4- Legales-Constitucionales (Tanto procesos judiciales -y otras medidas-) contra opositores que realiza el gobierno amparado por las leyes, como iniciativas 
ciudadanas que se inscriben dentro de marcos legales, como la propuesta impulsada por Tania Bruguera a través del Instituto Internacional de Activismo Hannah Arendt y la plataforma \#YoTambiénExijo, que busca que los cubanos que deseen un cambio se propongan como candidatos en las elecciones de 2018).

5- Represivas (Aquellas que se valen de la violencia tanto física como psicológica).

Sarelly Martínez (2012) indaga acerca de las estrategias de comunicación del EZLN y sobre su presencia en los medios y participación en las campañas presidenciales de México en el 2006. También se detiene en el contexto adverso en el que los zapatistas utilizaron la red informática para difundir sus mensajes y denomina como un boom la guerra virtual que emprendieron contra el gobierno. Aunque resalta el éxito de su estrategia, Martínez (2012) refiere que, a la larga, el propio EZLN se ha visto desgastado debido a que se quedaron como un sistema cerrado, un elemento que afecta también a la oposición cubana.

Jesús Galindo (1997) parte de afirmar que la tecnología de la información ha sido central en la configuración social y ecológica del EZLN, en tanto Internet ha sido un factor importante en la construcción de la imagen del fenómeno y en su proyección nacional e internacional. Sus consideraciones acerca de la constitución de una comunidad virtual que agrupa a actores de distinto orden y ámbito, desde lo nacional a lo internacional, desde los sectores populares hasta los medios y altos, de las clases semi ilustradas hasta las clases intelectuales, ofrece pauta para pensar también la configuración de la comunicación pública acerca de la oposición cubana en un entorno no necesariamente ligado al espacio físico.

Para Galindo (1997) la comunidad virtual es una configuración de espacios de colaboración que supone múltiples entidades independientes en evolución simultánea gracias a una interacción constante. "Su corazón es la voluntad de constituirse, es una producción simbólica colectiva de mundos representados y compartidos. En la comunidad virtual todos participan y construyen, todos comparten lo construido. Lo que garantiza la horizontalidad y acceso a la información es la estructura de la red, no hay centro, todos son modos de circulación y producción" (p.13). Habría que pensar, no obstante, si todas las comunidades virtuales comparten esa horizontalidad que parece más bien ideal, y si en el espacio virtual no se reproducen, como en el físico, las estructuras de poder.

En este sentido Markus Schulz (2014) plantea que el levantamiento zapatista en Chiapas ha sido considerado como el caso prototípico de conflicto social donde el uso de Internet desempeñó un papel instrumental, pero hace un llamado a la cautela respecto a la valoración del papel de Internet como herramienta en los movimientos sociales, matizando aspectos significativos que 
contribuyen ya sea a sobredimensionar o subestimar dicho papel.

Cada una de estas líneas de investigación se inserta en las áreas de competencia de la comunicación pública, de modo que estas investigaciones resultan un importante antecedente al mostrar los mecanismos de inserción en el espacio público mediático de un grupo rebelde mexicano cuyas condiciones de aislamiento y de acceso a las nuevas tecnologías presenta puntos de contacto con la de los grupos opositores en Cuba. También en ambos casos encontramos un desencuentro fundamental entre las perspectivas políticas de los gobiernos y de los movimientos disidentes que desafían lo público para visibilizar sus demandas. Además, en una y otra experiencia, buena parte de las redes de colaboración se tejen desde el extranjero y su comunicación pública se mueve de lo local a lo global y viceversa y se establece, en ese contexto, la constitución de una comunidad virtual, solidarizada alrededor de objetivos políticos.

\section{Consideraciones finales}

Si bien la oposición política ha ganado presencia en el ámbito de lo público y han surgido nuevas alianzas y proyectos entre estos grupos que buscan promover cambios democráticos en Cuba a través de la vía pacífica y aprovechando los marcos constitucionales vigentes, esto no equivale a una oposición más efectiva, ni con mayor ni mejor inci- dencia dentro de la isla. La oposición en Cuba sigue siendo dispersa, fragmentada y su discurso encuentra más eco en la opinión pública internacional, que dentro del país. Todo esto se deriva, en buena medida, del propio contexto de represión política que sufren los activistas y del aislamiento social al que están expuestos. Pero no puede obviarse que, de manera general, las demandas de la oposición no han logrado conectarse de modo efectivo con aspiraciones y necesidades concretas de la mayoría de la sociedad cubana y tampoco su discurso ha conseguido atraer el apoyo, ni la simpatía de otros grupos ciudadanos en la isla. La falta de transparencia y los nexos con el gobierno norteamericano comprometen su autonomía y le restan legitimidad a sus propuestas. Asimismo, el reciente rechazo de algunos opositores a la normalización de relaciones entre Washington y La Habana, unido a la celebración pública de algunos de esos mismos activistas por la elección de Donald Trump como presidente de Estados Unidos, refuerzan el recelo hacia una oposición en la que sobresalen grupos y líderes tendientes a alinearse con la derecha republicana y ultra conservadora de ese país.

Durante la evaluación de este artículo se produjo el fallecimiento de Fidel Castro, el 25 de noviembre de 2016. La noticia inmediatamente acaparó las agendas noticiosas internacionales que dieron seguimiento a los nueve días de duelo nacional establecidos para rendir tributo al líder de la revolución cubana. 
Lo público en la isla se vistió de luto, en parte mediado por directrices oficiales, en parte, sin duda, por manifestaciones espontáneas de pena, representadas en los días subsiguientes por los medios de comunicación nacionales y extranjeros, en algunos casos para exaltar las imágenes de dolor colectivo, en otros para desacreditarlas.

En un contraste extremo, buena parte de la comunidad cubana exiliada en Miami, en el Estado de La Florida, al sur de los Estados Unidos, se lanzó a las calles en la madrugada del 26 de noviembre para celebrar la muerte del ex mandatario. Este suceso reavivó las tensiones entre cubanos -y también entre extranjeros- de militancias distintas y de visiones divergentes acerca de la figura de Fidel Castro y de la revolución cubana. En tanto, unas pocas voces llamaban a respetar las diferencias y a tratar de entender cómo una misma figura podía significar cosas distintas según la experiencia vital de cada persona, un factor imprescindible para comprender por qué, en el entorno de lo público, la muerte de Castro generó imágenes, relatos y performances tan diversos y en los casos de Cuba y Miami, polarizados.

Al día siguiente del deceso las voces opositoras de la isla comenzaban a manifestarse acerca del tema en la prensa extranjera e independiente. Algunos explicitaron que no celebraban la muerte y que respetaban el luto ajeno, aun cuando no lo compartieran, tomando distancia así de las posturas asumidas por sus compatriotas de Miami, aunque se mostraron también respetuosos e incluso empáticos hacia el sentir de ese grupo. Sus declaraciones se enfocaron fundamentalmente en llamar a la unidad y a la acción en función seguir promoviendo cambios democráticos en la isla.

Las Damas de Blanco cancelaron, por primera vez en trece años, su habitual marcha en La Habana y Berta Soler manifestó su decisión de no salir a las calles para que el gobierno no lo asumiera como una provocación mientras rendían honores a su fallecido (Reuters, 2016). Ferrer, de UNPACU, Fariñas, de FANTU y Rodiles, de Estado de Sats, se refirieron además a un probable recrudecimiento de la represión contra la disidencia en el nuevo contexto. De cierta forma, todos reconocieron el peso político que había mantenido la figura de Castro, incluso después de que traspasara el poder a su hermano Raúl en 2006, así como su conexión con amplios sectores sociales (Acosta y Martínez, 2016; Torrens, 2016; Díaz, 2016). Por eso, para estos opositores, como para algunos de los académicos aquí citados, la desaparición física de Castro, quien gobernara la isla durante 47 años, representa un posible catalizador de las trasformaciones en el país.

Las predicciones acerca de los posibles cambios en Cuba tras la muerte de Castro sólo podrán ser evaluadas con el tiempo. Por el momento, este suceso coloca nuestro objeto de estudio en un entorno que se complejiza, en el que 
crecen las expectativas de cambio entre los grupos opositores y su visibilidad internacional. Al mismo tiempo, aumenta la incertidumbre acerca del futuro económico y político de la isla, abocada a las elecciones de 2018 en las que, según ha anunciado Raúl Castro, culminará su mandato y se espera, además de la elección de un nuevo presidente, la implementación de una nueva ley electoral entre cuyos cambios se prevé el establecimientos de un límite de diez años para los cargos políticos. Si la muerte de Fidel Castro marca un punto de quiebre -en el proceso revolucionario, en la historia de Cuba, de América, del mundo-, tocará analizar cómo esto incide en la configuración de la comunicación pública relativa a la oposición política de la isla, cuyos líderes, por lo pronto, al pronunciarse sobre el tema, se han insertado de modo estratégico en las agendas mediáticas internacionales.

Como si todo tema relativo a la isla desatara criterios encontrados, también la oposición política de Cuba genera tan- to loas como apologías. Abundan igualmente los silencios sobre el tema en algunos ámbitos, pero se encuentran, a la par de miradas en extremo parciales y atravesadas por la arenga política; otras, profundas, documentadas y analíticas sobre el fenómeno. Atender a estudios realizados por autores de procedencia diversa y con posturas $y$ compromisos políticos también diferentes ha revelado la variedad de puntos de vista sobre este tópico, lo cual reitera la necesidad del rigor metodológico y la reflexión constante. Entre las contribuciones de nuestro trabajo está el colocar a la oposición política de Cuba en el centro de un análisis que se articula alrededor de la comunicación pública y de su juego en este campo con otros agentes sociales como el Estado cubano, la sociedad civil nacional, los medios de comunicación y el gobierno de Estados Unidos, cada uno de los cuales, coincidentemente, se encuentra atravesando procesos de cambio, lo cual coloca nuestro objeto en una coyuntura de importantes reconfiguraciones.

\section{Referencias Bibliográficas}

Acosta, N.; Martínez, A.( 27 de noviembre de 2016). Sin la sombra de Fidel, disidentes esperan un giro en conmocionada Cuba. Reuters. Recuperado de http://ta. reuters.com/article/domesticNews/idLTAKBN13M0ST

Bobes, C. (2007). La nación inconclusa. (Re)constituciones de la ciudadanía y la identidad nacional en Cuba. México: Flacso.

CubaDecide. (2016). El plebiscito. Recuperado de https://cubadecide.com/

Debaveye, J. (2013). @clamontréal: émergence et institutionnalisation d'une expertise militante dans le micro-médias. (Tesis de doctorado inédita). Facultad de Estudios 
Superiores y Posdoctorales, Universidad de Laval, Québec Recuperado de chrome-extension://oemmndcbldboiebfnladdacbdfmadadm/http://theses.ulaval.ca/archimede/fichiers/29665/29665.pdf

De León, S. (enero-junio de 2011). Comunicación pública, transición política y periodismo en México: el caso de Aguascalientes. Comunicación y Sociedad, (15), 4369. Recuperado de chrome-extension://oemmndcbldboiebfnladdacbdfmadadm/ http://www.redalyc.org/pdf/346/34615397003.pdf

Diario de Cuba. (22 de marzo de 2016). Barack Obama se reúne en La Habana con un grupo de opositores. Recuperado de http://www.diariodecuba.com/derechoshumanos/1458663689_21129.html

Díaz, L. (26 de noviembre de 2016). Reacciones encontradas entre cubanos de la isla por muerte de Fidel Castro. Martí Noticias. Recuperado de http://www.martinoticias.com/a/cierran-centros-nocturnos-habana-noticia-muerte-fidel-castro/134223.html

Dilla, H. (23 de junio de 2014). Cuba: los nuevos campos de la oposición política. Real Instituto Elcano. Recuperado de http://www.realinstitutoelcano.org/wps/portal/ rielcano/Imprimir?WCM_GLOBAL_CONTEXT=/elcano/Elcano_es/Zonas_es/ ARI30-Dilla-Cuba-nuevos-campos-oposicion-politica

Dilla, H.; Oxhorn, Ph.(1999). Virtudes e infortunios de la sociedad civil en Cuba. Revista Mexicana de Sociología, 61 (4), pp. 129-148. Recuperado de chrome extension://oemmndcbldboiebfnladdacbdfmadadm/http://nuso.org/media/articles/ downloads/2945_1.pdf

EFE. (26 de noviembre de 2016). Guillermo Fariñas teme que la muerte de Castro eleve los actos de represión en Cuba. Recuperado de http://www.efe.com/efe/america/politica/guillermo-farinas-teme-que-la-muerte-de-castro-eleve-los-actos-represion-en-cuba/20000035-3108646

Fernández, O. (16 de octubre de 2011). Cuba's Socialist Transition. Economic Adjustment and Sociopolitical Challenges. Rebelión. Recuperado de http://www.rebelion.org/noticia.php?id $=134084$

Freedom House (2016). Cuba. Freedom in the World 2016. Recuperado de https:// freedomhouse.org/report/freedom-world/2016/cuba

Freedom House (2015). Cuba. Freedom on the Net 2014. Recuperado de https:// freedomhouse.org/report/freedom-net/2014/cuba

Galindo, J. (5 de junio de 1997). Comunidad virtual y cibercultura: el caso del EZLN en México. Estudios sobre las Culturas Contemporáneas, 3 (5), 9-28. Recuperado de http://www.redalyc.org/articulo.oa?id=31600502 
Gámez, N. (2013). Rap is war': Los Aldeanos and the politics of music subversion in contemporary Cuba. TRANS-Transcultural Music Review, 17. Recuperado de chrome-extension://oemmndcbldboiebfnladdacbdfmadadm/http://www.sibetrans. com/trans/public/docs/trans-17-11.pdf

Geoffray, M. L.; Chaguaceda, A. (julio-diciembre de 2014). Medios de Comunicación y cambios en la política de información en Cuba desde 1959. Temas de Comunicación, (29), 171-196.

ITU (2014). Informe sobre Medición de la Sociedad de la Información 2014. Resumen Ejecutivo. Recuperado de https://www.itu.int/en/ITU-D/Statistics/Documents/publications/mis2014/MIS_2014_Exec-sum-S.pdf

Leyva, A.; Somohano, A.(julio-septiembre de 2008). Los intelectuales y la esfera pública en Cuba: el debate sobre políticas culturales. Temas, 59, s/p. Recuperado de http://temas.cult.cu/articulo_academico/los-intelectuales-y-la-esfera-publica-en-cuba-el-debate-sobre-politicas-culturales/

Martínez, S. (2012). Estrategias de comunicación del EZLN en tiempos de incertidumbre. Diálogos de la comunicación. Recuperado de chrome extension://oemmndcbldboiebfnladdacbdfmadadm/http://dialogosfelafacs.net/wp-content/ uploads/2015/75/75-revista-dialogos-estrategias-de-comunicacion-de-elzn.pdf

Morin, M. CH. (2009). Le quartier virtuel chinois de Quebec: lieu de creation d'une communauté virtuelle chinoise locale? (Tesis de maestría inédita). Facultad de Estudios Superiores, Universidad de Laval, Quebec. Recuperado de chrome- extension:// oemmndcbldboiebfnladdacbdfmadadm/http://theses.ulaval.ca/archimede/fichiers/26866/26866.pdf

Núñez, M. (julio de 2014). U.S. Proposals for an Unwanted Transition in Cuba: A Critique. Latin American Perspectives, 41(4) 147-163.

Proulx, G. (2007). Les communautés interprétatives d'un enjeu environnemental médiatisé : le cas de l'exportation en vrac de l'eau douce canadienne (Tesis de maestría inédita). Facultad de Estudios Superiores, Universidad de Laval, Québec. Recuperado de chrome extension://oemmndcbldboiebfnladdacbdfmadadm/http:// theses.ulaval.ca/archimede/fichiers/24867/24867.pdf

Rovira, G. (2005). El Zapatismo y la Red Transnacional. Razón y Palabra. Recuperado de http://www.razonypalabra.org.mx/anteriores/n47/grovira.html

Schulz, M. (2014). Nuevos medios de comunicación y movilización transnacional: el caso del Movimiento Zapatista. Perfiles latinoamericanos, vol.22 N 44. Recuperado de http://www.scielo.org.mx/scielo.php?script=sci_arttext\&pid=S0188765320140 $00200007 \& \operatorname{lng}=\mathrm{es} \& \mathrm{nrm}=\mathrm{iso \& t \operatorname {lng } = \mathrm { es }}$ 
Torrens, M. (27 de noviembre de 2016). El líder de la oposición en Cuba: "La caída del régimen llegará en 2020 con el sustituto de Raúl”. El Español. Recuperado de http://www.elespanol.com/mundo/america/20161126/173733276_0.html 